\title{
Successful endoscopic resection using a bipolar snare for an adenoma overlying a transverse colonic lipoma
}

Colonic lipomas are uncommon mesenchymal neoplasms, and the transverse colon appears to be the rarest site for coIonic lipomas [1]. Furthermore, it is rare to have an adenomatous polyp growing over the mucosal surface of a colonic lipoma.

A 72-year-old man was referred to our hospital from a private clinic for a colonic polyp overlying a submucosal tumour (SMT). The biopsied specimen taken at the private clinic revealed a tubular adenoma with fatty tissue. Endoscopy showed a type 0 -Ila polyp, $12 \mathrm{~mm}$ in diameter, overlying a sessile SMT, with the mass having a positive cushion sign, in the transverse colon ( $\mathbf{F i g} \mathbf{1} \mathbf{a}$ ). Magnifying narrow-band imaging revealed regular vessels and surface patterns ( Fig.1 b); therefore, we diagnosed an adenoma overlying a lipoma. We successfully performed hot snare polypectomy with a bipolar electrode ( $\vee$ Video 1 ), and naked fat was visible at the base of the resection site ( $\mathbf{F i g . 1} \mathbf{c}$ ). There were no adverse events. Histological examination showed a tubular adenoma with low grade dysplasia and the fatty tissue was compatible with a lipoma ( Fig. 2).
Endoscopic polypectomy of a colonic lipoma with a monopolar electrode is known to carry a risk of perforation as the lipomatous tissue has a low water content and therefore conducts electrosurgical current less efficiently [2]. Therefore, increasing the power to assist endoscopic resection may damage the adjacent bowel wall with subsequent perforation [3]. Placing an endoloop prior to an endoscopic resection can prevent perforations [4]; however, in our case, the shape of the SMT was sessile, meaning the endoloop wire would slip during closure so could not be placed. With the bipolar instrument, the electric current only flows from the snare toward a sheathed electrode, thereby avoiding deep thermal injury [5]. As a result, we were able to simply and safely resect the adenoma overlying the colonic lipoma using a bipolar snare, without any perforation.

Endoscopy_UCTN_Code_TTT_1AQ_2AD
Competing interests

The authors declare that they have no conflict of interest.

The authors

Shozo Osera' ${ }^{1}$, Tomoaki Shinohara ${ }^{1}$, Akihisa Tomori', Tamaki Momoi' ${ }^{1}$, Hideki Fukushima', Takeshi Hisa ${ }^{1}$, Satoshi Shiozawa ${ }^{2}$

1 Department of Gastroenterology, Saku Central Hospital Advanced Care Center, Nagano, Japan

2 Department of Pathology, Saku Central Hospital Advanced Care Center, Nagano, Japan

Corresponding author

Shozo Osera, MD, PhD

Department of Gastroenterology, Saku Central Hospital Advanced Care Center, 3400-28, Nakagomi, Saku, Nagano 385-0051, Japan

Fax: +81-267-887354 shou0122@hotmail.com
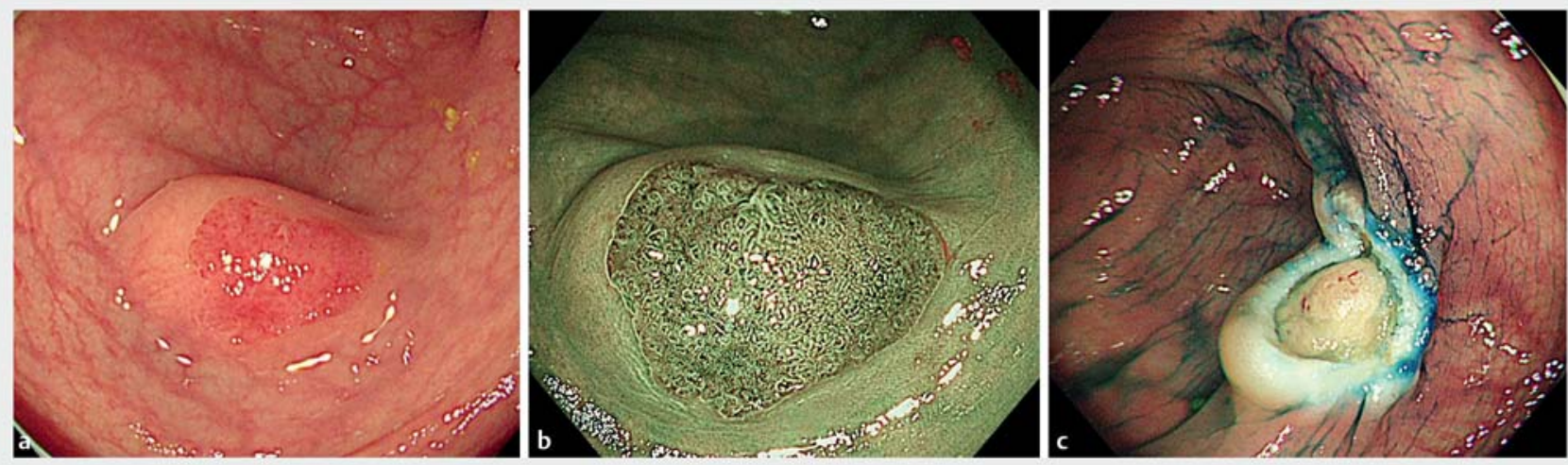

Fig. 1 Endoscopic images showing: a a type 0-lla polyp overlying a sessile submucosal tumour in the transverse colon; $\mathbf{b}$ narrow-band imaging revealing regular vessels and surface patterns; $\boldsymbol{c}$ visible naked fat at the base of the resection site. 


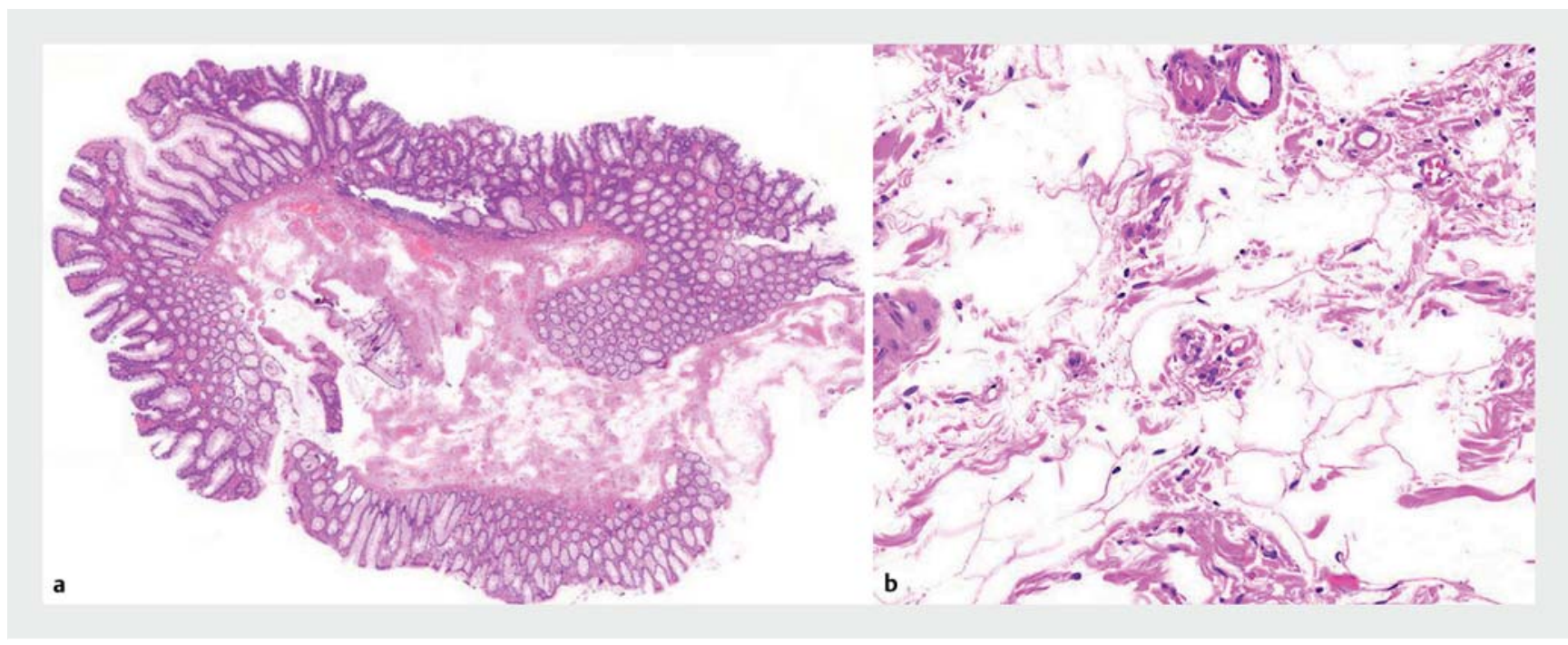

Fig. 2 Pathological findings showing: a a tubular adenoma with low grade dysplasia on fatty tissue; $\mathbf{b}$ a lipoma beneath the tubular adenoma.

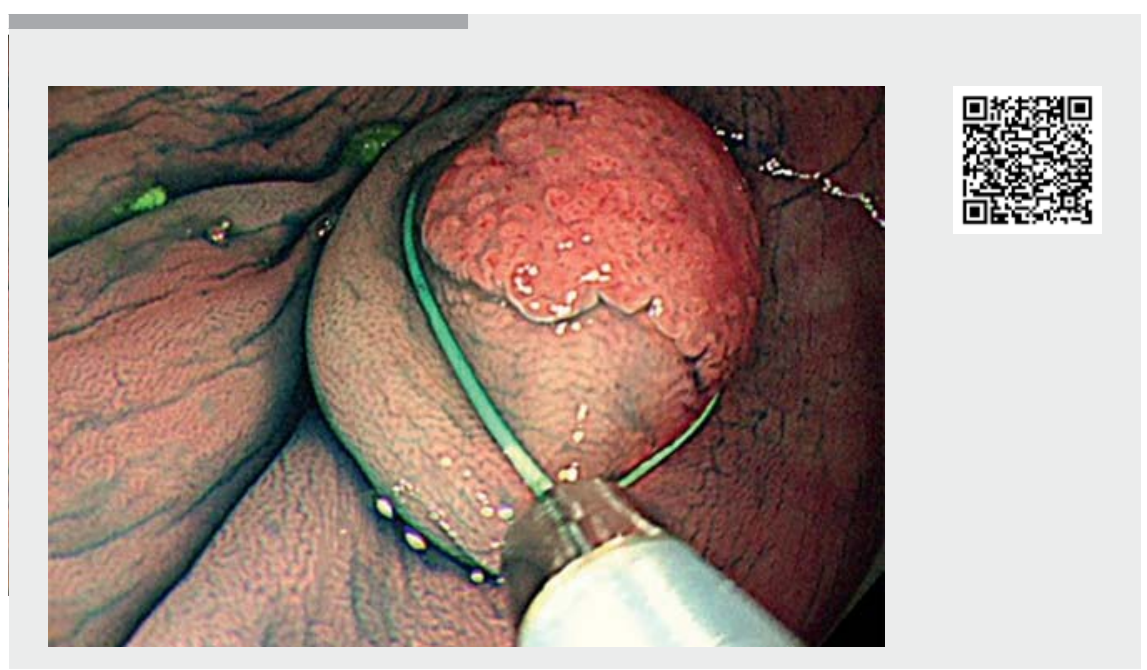

Video 1 Successful endoscopic resection using bipolar snare for adenoma overlying a transverse colonic lipoma.

\section{References}

[1] Moschetta M, Virelli R, Laricchia F et al. Lipoma of the transverse colon covered by tubulovillous adenoma: a rare indication for surgical treatment. G Chir 2018; 39: 63-66

[2] Bahadursingh AM, Robbins PL, Longo WE. Giant submucosal sigmoid colon lipoma. Am J Surg 2003; 186: 81-82

[3] Geraci G, Pisello F, Arnone E et al. Endoscopic resection of a large colonic lipoma:
Bibliography

DOI https://doi.org/10.1055/a-1134-4567

Published online: 27.3.2020

Endoscopy 2020; 52: E372-E373

(c) Georg Thieme Verlag KG

Stuttgart · New York

ISSN 0013-726X

\section{ENDOSCOPY E-VIDEOS}

https:|/eref.thieme.de/e-videos

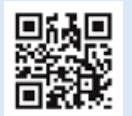

Endoscopy E-Videos is a free access online section, reporting on interesting cases and new techniques in gastroenterological endoscopy. All papers include a high quality video and all contributions are freely accessible online.

This section has its own submission website at

https://mc.manuscriptcentral.com/e-videos 